\title{
Verruciform xanthoma of the vulva: case report
}

\author{
G DE ROSA, * E BARRA,* R GENTILE, * A BOSCAINO, * B Di PRISCO, * F AYALA $\dagger$ \\ From the Institutes of * Pathology and $†$ Clinical Dermatology, II Faculty of Medicine and Surgery, University of \\ Naples, Naples, Italy
}

SUMMARY A rare case of verruciform xanthoma of the vulva is reported. Diagnosis was made possible by histopathological examination and immunohistochemical staining.

Verruciform xanthomas generally occur in the oral cavity. To the best of our knowledge, this is the third reported case of the tumour located on the genital mucosa. Immunohistochemical study supported the histiocytic origin of the lesion.

Clinically, verruciform xanthomas may mimic other verrucous lesions of the vulva, such as seborrhoeic keratosis, verruca simplex, condyloma acuminatum, verrucous carcinoma, or erythropasia of Queyrat, or conditions such as histiocytosis, cutaneous lipidosis, or granular cell myoblastoma. The characteristics that differentiate those conditions from verruciform xanthoma, which can be seen only on histology, are given.

In 1971 Shafer first described a case of verruciform xanthoma. ${ }^{1}$ Since then, about 50 cases of this rare tumour have been reported. ${ }^{23}$ Most of the lesions were located in the oral cavity, and in only five cases were they located extraorally. ${ }^{47}$ Two occurred on the vulva ${ }^{4}$ and three were found on male genitalia. ${ }^{5-7}$

To the best of our knowledge, this is the third report of verruciform xanthoma of the vulva. Lesions at this anatomical site have previously been characterised immunohistochemically.

\section{Case report}

A woman aged 65 was admitted to hospital because of persistent bleeding caused by uterine leiomyomas. On clinical examination a plaque like lesion $1.5 \mathrm{~cm}$ in diameter was found on her vulva. Excisional biopsy of the lesion was undertaken while she underwent total hysterectomy with bilateral adnexectomy. Hysterectomy showed leiomyomatosis of the uterine corpus and hyperplasia of the endometrium.

Histological examination of the biopsy specimen of the vulvar lesion showed an exophytic papillary growth with parakeratosis, acanthosis, and regular elongated rete ridges, but no cytological atypia (fig 1). The papillary dermis was the site of an infiltrate, which

Address for reprints: Professor Gaetano De Rosa, Istituto di Patologia, II Facoltà di Medicina e Chirurgia, Via Pansini 5, 80131 Napoli, Italy

Accepted for publication 22 February 1989 was mainly represented by histiocytic cells arranged mostly in clusters. These cells were characterised by abundant foamy cytoplasm (fig 2). Staining with periodic acid Schiff (PAS) stain showed only a few foamy histiocytes, before and after diastase digestion. A PAS reaction caused by glycogen was therefore excluded. Fat stains were precluded because the tissue had been processed routinely. Lysozyme immunoreactivity (Dakopatts, Denmark, at a dilution of 1:100) was also present (fig 3).

\section{Discussion}

Verruciform xanthoma has well defined histological

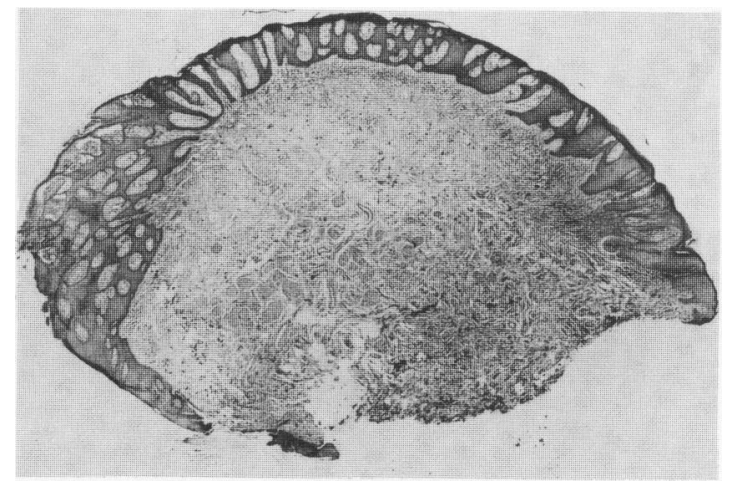

Fig 1 Low power histological section of verrucous lesion showing regular elongated rete ridges (haematoxylin and eosin). 


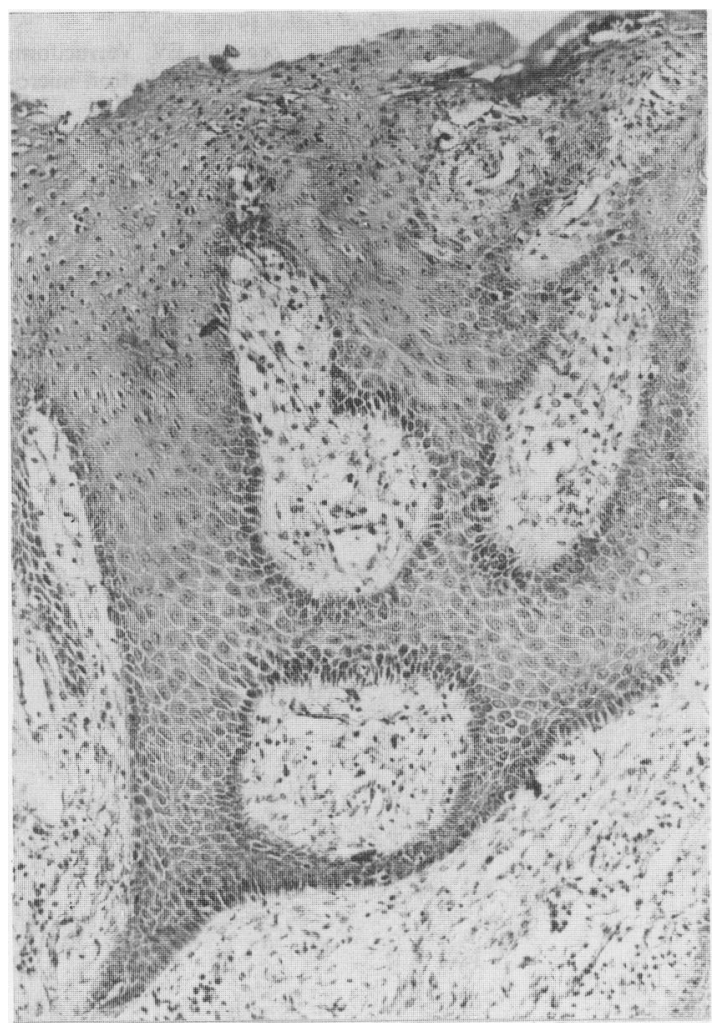

Fig 2 Clusters of foam cells in papillary dermis between rete pegs (periodic acid Schiff).

features that generally permit a definitive correct diagnosis. It generally presents as a hyperkeratotic, cauliflower like, verrucous or papillomatous lesion. Clinically, it may mimic other verrucous lesions of the vulva, such as seborrhoeic keratosis, verruca simplex, condyloma acuminatum, verrucous carcinoma, or erythroplasia of Queyrat. Histiocytosis, cutaneous lipidoses, or granular celll myoblastoma may also be simulated.

On microscopy, however, verruca vulgaris and condyloma acuminatum do not show xanthoma cells in the papillary dermis. On the other hand, these lesions of viral aetiology show characteristic epithelial cell vacuolation in the upper Malpighian stratum.

Erythroplasia of Queyrat characteristically shows pronounced cytological atypia, and foam cells are not found in that condition.

The presence of parakeratosis and the absence of epithelial cell atypia and mitoses may sometimes make it difficult to exclude verrucous carcinoma. The presence of circumscribed bulbous rete ridges help in the differential diagnosis.

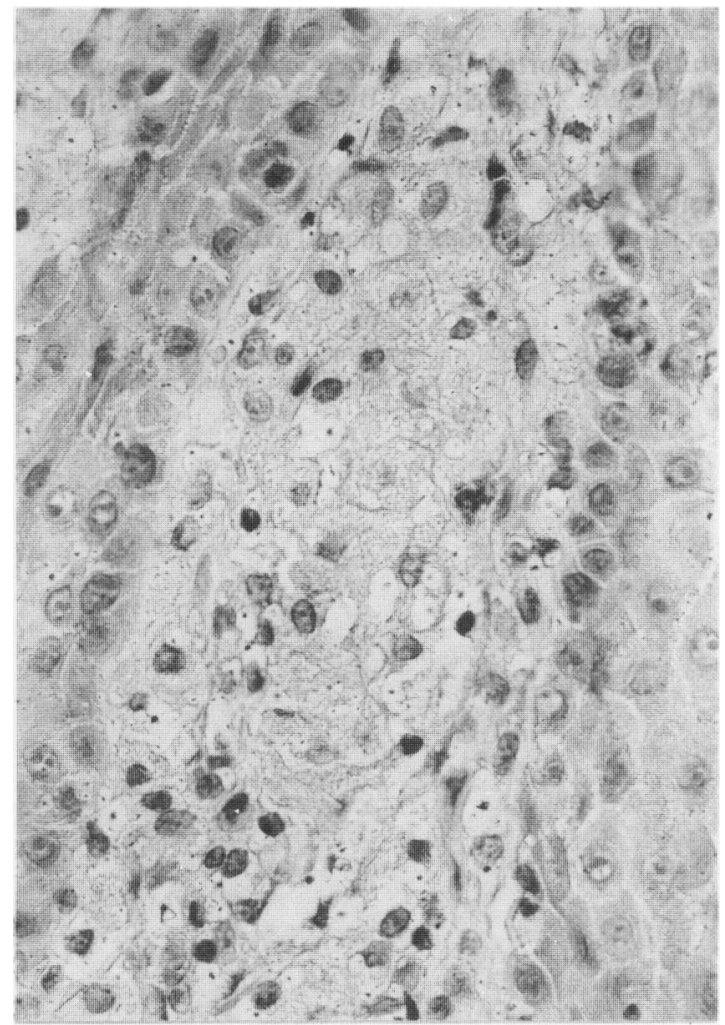

Fig 3 Foam cells with pale lysozyme cytoplasmic staining (Papanicolaou's stain).

Xanthoma cells are present in the papillary and reticular dermis in cutaneous lipidoses and histiocytosis; lipid laden histiocytes are therefore common in those conditions.

Finally, granular cell myoblastoma is sometimes characterised by cells in the papillary dermis that mimick a lipid content, in addition to pseudoepitheliomatous hyperplasia of the overlying epithelium. Nevertheless, deep dermal cells contain eosinophilic, PAS staining, diastase resistant granules. The use of antiserum to $S 100$ protein is useful to identify the cells of granular cell tumours.

An inflammatory origin has been postulated for verruciform xanthoma, as epithelial breakdown could probably elicit a foam cell response. ${ }^{3}$ On the other hand, Santa Cruz and Martin proposed a viral aetiology, despite the absence of intraepithelial inclusion and vacuolisation. ${ }^{4}$ In oral lesions, ultrastructural studies have shown foam cells under the epithelium. The foam cells corresponded to histiocytes and had intensely osmiophilic lipid containing vacuoles, which stained with Sudan black B and 
scarlet red fat stain. $^{3}$ Our immunohistochemical studies supported the histiocytic origin of foam cells under the epithelium, by means of antihuman lysozyme immunoreactivity.

In conclusion, verruciform xanthoma is a localised lesion whose correct diagnosis requires surgical excision and careful histological examination.

\section{References}

1 Shafer WB. Verruciform xanthoma. Oral Surg 1971;31:784-9.

2 Cobb CM, Holt R, Denis FR. Ultrastructural features of the verruciform xanthoma. J Oral Pathol 1976;5:42-51.

3 Zegarelli DJ, Zegarelli-Schmidt EC, Zegarelli EV. Verruciform xanthoma. A clinical, light microscopic, and electron microscopic study of two cases. Oral Surg 1974;38:725-34.

4 Santa Cruz DJ, Martin SA. Verruciform xanthoma of the vulva. Am J Clin Pathol 1979;71:224-8.

5 Kraemer BB, Waldemar A, Schmidt WA, Foucar E, Rosen T. Verruciform xanthoma of the penis. Arch Dermatol 1981; 117:516-8.

6 Ronan SG, Bolano J, Manaligot JR. Verruciform xanthoma of penis. Light and electron-microscopic study. Urology 1984; 23:600-3.

7 Al-Nafussi AI, Azzopardi JG, Salm R. Verrucous xanthoma of the skin. Histopathology 1985;9:245-52. 